\title{
Consequences of climatic change for the human environment
}

\author{
M. J. Scott ${ }^{1}$, N. J. Rosenberg ${ }^{2}$, J. A. Edmonds ${ }^{1}$, R. M. Cushman ${ }^{3}$, R. F. Darwin ${ }^{1}$, G. W. \\ Yohe $^{4}$, A. M. Liebetrau ${ }^{1}$, C. T. Hunsaker ${ }^{3}$, D. A. Bruns ${ }^{5}$, D. L. DeAngelis ${ }^{3}$, J. M. Hales ${ }^{1}$ \\ ${ }^{1}$ Battelle Memorial Institute, Pacific Northwest Laboratories, Battelle Boulevard, PO Box 999, Richland, Washington 99352, USA \\ ${ }^{2}$ Resources for the Future, 1616 P Street N.W., Washington, D.C. 20036, USA \\ ${ }^{3}$ Environmental Sciences Division, Oak Ridge National Laboratory, PO Box 2008, Oak Ridge, Tennessee 37831, USA \\ ${ }^{4}$ Wesleyan University, Middletown, Connecticut 06457, USA \\ ${ }^{5}$ Idaho National Engineering Laboratory, PO Box 1625, Idaho Falls, Idaho 83415, USA
}

\begin{abstract}
This paper provides a comprehensive overview of the state of the science in estimating potential effects of climate change on the human environment. The paper provides an overview of the state of effects research and outlines the analyses required in order to make adaptive policy. It compares approaches that have been taken for measuring the human consequences of climate change, and outlines the results of climate change impact studies that have been performed both on individual sectors and entire regions. The paper also discusses both the results of studies of historical environmental changes that serve as analogs for potential future climate change and the major sources of uncertainty. The paper concludes with a summary of effects, knowns and unknowns, and directions for future research. In general, future effects research needs to be targeted on regions rather than individual resources; it must take the timing of resource effects and technological change explicitly into account; and it must directly address uncertainty using new and more efficient computational techniques, as opposed to brute-force Monte Carlo estimation.
\end{abstract}

\section{INTRODUCTION}

This paper is concerned with the potential effects of climate change on the human environment. Although much has been written in both the scientific literature and popular press concerning the 'greenhouse effect' and its potential consequences for natural and human resources, and although other overviews of impact studies exist (e.g. Riebsame 1989 reviews many of the studies and methods used in assessing the impact of climate on human society, and Topping 1989 contains a large number of papers on impacts and planning and energy policy responses), we have yet to see a short, comprehensive overview of the state of the science that fully explains the existing gaps in our knowledge of these effects. Also, while much has been written on policy to control the greenhouse effect, we believe that existing emissions rates and limited prospects for their early control already may have ensured that some climate change will take place sometime in the next century, increasing the urgency of effects research. However, we have yet to see serious policy discussions of how societies might reasonably adapt to a warmer world, or a review of research may be needed to guide such adaptations. This paper attempts to fill both needs by providing an overview of the state of effects research and outlining the analyses required to make adaptive policy. It compares approaches that have been taken for measuring the human consequences of climate change (Section 1); outlines the results of climate change impact studies that have been performed both on individual sectors (Section 2) and on entire regions (Section 3); discusses the results of studies of historical environmental changes resembling the 
effects of potential future climate change (Section 4) and the major sources of uncertainty (Section 5); and concludes with a discussion and summary of effects, knowns and unknowns, and directions for future research (Section 6).

\section{APPROACHES TO EXAMINING CONSEQUENCES}

Several approaches have been taken in the attempt to anticipate the possible effects of global climate change on the human environment. The development of climate impact assessment has incorporated increasing sophistication in our projections of future climate and in our understanding of the relationship between climate and the human environment.

Some of the first assessments of climate impacts (e.g. Waggoner 1983) were based on arbitrary 'scenarios' of climate change, intended primarily to demonstrate the sensitivity of many resources to such change. The next generation of analyses (e.g. Rosenzweig 1985, Cohen 1986) used month-by-month or season-by-season simulations of climate from general circulation models (GCMs) for various points or gridcells on the surface of the earth. Most recently, analyses such as that of Wilks (1988) have used weather-generating techniques to produce realistic scenarios of daily weather series from the temporally aggregated GCM output that is made available for climate impact studies. Gates (1985) suggested the use of spatially nested models or empirical orthogonal functions to relate the spatially coarse GCM output to local weather, but such techniques have not yet been incorporated in climate impact assessment. With a few minor exceptions (e.g. some sections of Smith \& Tirpak 1988) most studies have analyzed only steady state effects of climate change (typically the radiative equivalent of a doubling of atmospheric $\mathrm{CO}_{2}$ concentration - hereafter called $2 \times \mathrm{CO}_{2}$ ) with today's technology. There is a general need to examine the consequences of time-dependent warming scenarios under the technological regime that would prevail when the warming occurs.

The feedback reactions of human institutions on biophysical environmental relationships may largely ameliorate or may exacerbate the effects of climate alone (Glantz 1988). Some studies, e.g. some of those of drought in the Sahel in Africa in the 1970s (Garcia 1981), sea level rise (e.g. Titus 1988), agriculture (Parry et al. 1988a, b), and whole regions (Smith \& Tirpak 1988), have recognized these feedbacks. A fully inte-

\footnotetext{
- We acknowledge the difficulty of technological forecasting. but think that carefully-thought-out technological scenarios must at least be attempted
}

grated approach that also recognizes interactions between sectors was proposed by Callaway et al. (1982), was partially implemented by Parry et al. $(1988 \mathrm{a}, \mathrm{b})$ for agriculture in some regions, and is now being implemented for a single region in a Department of Energy (DOE)-sponsored study of the effects of climate change (Cushman et al. 1989).

Without a truly coordinated national or international program in climate impact assessment, most of the studies have focused on particular aspects of individual resource sectors in individual regions (e.g. Blasing \& Solomon 1984, Rosenzweig 1985, Cohen 1986, Gleick 1987a, Miller et al. 1987, Pastor \& Post 1988). These sectoral studies are described in Section 2. Recent attempts focus on potential climate impacts in entire regions, as described in Section 3 .

Another approach has been to examine the actual response of the human environment to actual past climatic variation, the so-called analog approach (see Section 4). It is not known whether past climate patterns are a good proxy for greenhouse-induced changes in the future; and because of data limitations, such studies are usually very restricted in their temporal and spatial extent.

\section{FINDINGS FROM SECTORAL STUDIES}

The results of existing studies for individual sectors have taught us much about the probable impacts of climate change and have identified many of the major remaining unknowns. Many of the unknowns, such as the effects of climate change on local weather, are common to several of the sectors.

\section{Energy}

The state of knowledge regarding the sensitivity of energy systems to climate change is primitive. Jaeger (1983) surveys the subject of climate effects on energy systems in a short chapter, and the US Environmental Protection Agency (EPA) (Smith \& Tirpak 1988) reviews potential effects of climate change on US electric utilities. In general, the field is still in the process of cataloging the nature of $\mathrm{CO}_{2}$ /climate sensitivities and developing crude measures of sensitivity.

Most present short- and medium-term U.S. energy forecast models of the residential and commercial sectors use heating and cooling degree-day variables to forecast energy demand. Statistically derived measures of this weather sensitivity vary from small (DOE 1989), to relatively large (Klan et al. 1989). However, these models generally do not capture the long-term response of energy consumption patterns to climate. In 
the long term, residential and commercial winter heating demand likely would decrease with higher average winter temperatures, reducing oil, gas and electricity consumption. Higher average summer temperature would mainly increase the demand for electricity as the use of air conditioning increases. In the agricultural sector, higher temperatures would likely result in increased energy demand for irrigation pumping, but reduced demand for crop drying. Industrial energy demand is largely insensitive to either weather or climate, although industrial output (and actual energy usage) may be supply-constrained by severe weather. Existing statistical analyses have not explored the relationship of transportation energy demand to climate, but warmer winters should increase transport activity and energy demand. Warmer summers should tend to increase the use of mobile air conditioners and energy demand fas well as the demand for chlorofluorocarbons (CFCs) or CFC substitutes].

The production of conventional oil, gas and coal is unlikely to be affected by climate, although less severe winter conditions could lower Arctic region supply costs. One effect that could increase Arctic costs is permafrost decay, which could create problems for infrastructure such as pipelines (e.g. Maxwell \& Barrie 1989). The availability and operation of hydroelectric power could be indirectly affected by climate through precipitation and evaporation patterns. Changes in hydrology and average climate could similarly affect the availability and design of power plant cooling systems.

The production capacity of renewable energy supplies, such as solar, wind, ocean thermal energy conversion (OTEC), and biomass, is potentially more sensitive to climate change than conventional energy supplies. Temperature, cloud cover, wind vectors, and their associated variances affect the production of solar, wind, and OTEC energy. It is unclear whether the combination of increased $\mathrm{CO}_{2}$ and changed climate would increase or decrease total energy productivity from biomass. Biomass waste as an energy source could be affected by productivity of forests. Average temperature and pressure conditions can also affect the availability of recoverable methane release from land fills.

\section{Agriculture}

Current projections of world population and income suggest that in the 50 to $75 \mathrm{Yr}$ expected for $2 \times \mathrm{CO}_{2}$ warming to occur (Bolin et al. 1986) global demand for food and fiber will grow at an annual percentage rate about half that of the last 30 to $40 \mathrm{yr}$ (World Bank 1984). If changes are as gradual as most studies suggest, the negative impacts would likely not overwhelm the pros- pective gains in worldwide productivity from even modest rates of technical advance (Easterling et al 1989). This would especially be true if increased atmospheric $\mathrm{CO}_{2}$ proves to be as effective a fertilizer in the field as it has in laboratory experiments. Thus, it appears likely that, overall, the future rate of growth in the worldwide demand for food and fiber can be met (Crosson \& Rosenberg 1989), even with most commonly projected climatic changes

At the regional scale, the nature of changes in agricultural capacity in a biophysical sense is uncertain because GCMs disagree about the effects of $2 \times \mathrm{CO}_{2}$ warming on regional climates (Schlesinger \& Mitchell 1985). Shifts among regions in agricultural comparative advantage could present some affected countries with difficult adjustment problems, while others, such as Canada, might benefit from comparative advantage (Smit 1989). For example, some of the GCMs indicate both hotter and drier conditions in midlatitudes. Studies based on that scenario (e.g. Blasing \& Solomon 1984) conclude that the American cormbelt would shift far to the north and east.

Countries losing agricultural comparative advantage because of climate change can be expected to either: (1) protect their agriculture by restricting imports from newly advantaged producers (despite the economic cost); (2) support research to develop appropriate technologies including better adapted crop varieties and animals; or (3) import more of the needed food and fiber while diverting investment from agriculture to other more productive sectors (Easterling et al. 1989). The first option may be invoked for reasons of national food security. The second option requires that national and international agricultural research institutions continue to develop and transfer new varieties and technologies to the farm sector. The third option requires confidence in the stability of the international trading system.

Warming greater than that predicted to result from $2 \times \mathrm{CO}_{2}$ or occurring in a much shorter time frame than the second third of the next century would pose more difficult problems for world agriculture than discussed above. Global agricultural capacity would not keep pace with rising demand, with the result that economic and environmental costs would be sharply higher.

\section{Water resources}

Global warming will accelerate the hydrologic cycle with a resulting increase in average global precipitation and evaporation estimated at between 7 and $15 \%$ (e.g. Bolin et al. 1986). However, because climate models do not agree even on the direction of change in annual precipitation for many regions, the impacts on 
regional water supplies are highly uncertain (Frederick \& Gleick 1989). In areas such as northern California where precipitation is currently dominated by winter snowfall and runoff is dominated by spring snow melt, warmer temperatures could produce dramatic relative increases in winter rain, earlier spring melting, and changes in seasonal runoff patterns, even with constant annual precipitation (Gleick $1987 \mathrm{a}, \mathrm{b}$ ).

The impacts of climate change on regional water supply and demand are uncertain. GCMs indicate possible changes in average annual precipitation for any given region on the order of plus or minus $20 \%$. Since runoff is essentially the difference between precipitation and evapotranspiration (which increases with higher temperatures), impacts on runoff can be even greater. Where runoff decreases, water quality in streams and rivers will decline unless pollutant loads also decrease. Water use in urban and suburban areas will probably increase with increasing temperature. In agriculture, irrigators would tend to use more water to compensate for higher transpiration rates, although higher $\mathrm{CO}_{2}$ levels reduce transpiration increasing the plant's resistance to vapor transfer into the air (Rosenberg 1981). Transpiration rates may also be raised or lowered as a result of (as yet unpredictable) changes in cloudiness, humidity and windiness (Martin et al. 1989, Rosenberg et al. 1989).

The relative values of water for alternative uses will likely change. Drinking and domestic uses will remain top priorities, but changes in seasonal and annual supplies may alter the relative benefits of allocating water and reservoir capacity to flood control, power generation, fish habitat, or consumptive uses such as irrigation. Hydroelectric power might become more attractive as a means of both abating the greenhouse effect and adapting to increased power demands that might accompany it (Frederick \& Gleick 1989). However, supplying this increased hydroelectric power would depend upon the availability of water at existing hydroelectric sites and/or appropriate new sites, which are becoming increasingly scarce in many parts of the world.

Adaptations to cilmate change could involve construction of new dams and reservoirs, interbasin transfers of water, and development of 'unconventional' sources of water - e.g. desalinization; recycling of industrial, municipal, and agricultural waste water; and weather modification. Lacking sufficient guidance on the specifics of future climatic conditions, water managers and planners are unlikely to invest in any of these measures unless factors other than climate change already justify them. However, water managers may already be willing to invest in techniques that improve the operation of existing infrastructure and in research and technological innovations to accomplish this end. The prospect of future climate change might hasten such investments (Frederick \& Kneese 1989).

\section{Forests, unmanaged ecosystems, and biodiversity}

Anticipated global warming could occur in a matter of decades, possibly outrunning natural rates of forest migration, which occur on millennial time scales (Batie \& Shugart 1989). If so, existing forests will become increasingly stressed and more susceptible to pest iøfestation, disease, and eventually, fire (Clark 1988). Gradually, existing forests will be replaced by other forms of vegetation or by forests with a different species mix (Sedjo \& Solomon 1989).

Tree growth is generally limited by lack of summer warmth in the high latitudes and by heat and lack of water in the mid-latitudes. The effects on forests would likely be modest in the tropics, where temperature changes are expected to be least. With global warming, the boreal forests would likely migrate northward onto the currently unforested tundra, provided adequate precipitation and soils exist. Simulations (Solomon 1986, Pastor \& Post 1988) indicate that the greatest transitions occur at the boreal/cool temperate border. Some mid-latitude forests could disappear, especially if the projected increases in tree growth and moisture-saving effects of high $\mathrm{CO}_{2}$ and improved plant water use efficiency (Rosenberg 1981) do not materialize. Warming in mountainous terrain would cause species to move to higher elevations (Sedjo \& Solomon 1989).

Rapid change in climate threatens to reduce ecosystem biodiversity (Batie \& Shugart 1989). Some existing species of plants and animals would be unable to adapt because they are not sufficiently mobile to migrate at the rate required for survival (Davis $1989 a$, b). While the economic value of biodiversity is difficult to quantify, it is undoubtedly substantial.

Adaptation of the forest sector to changing climate will not be simple, but would likely include earlier harvests of unsuited species and salvage operations in older stands; seeding and thinning (which are costly) in younger stands; and active planting of trees adapted to hotter and drier (or wetter - it is not clear which) climates in harvested stands (Sedjo \& Solomon 1989). Introduction of new varieties is a much slower process in forestry than in agriculture. At least in the first decades, adaptation may involve changes in the species mix that could require costly adjustments in the logging and processing industry. Also, the long growing periods for trees add the economic risk of inappropriate species choice for changing climate conditions, inhibiting investment in trees and mills to process them. The geography of production forestry will 
change, with some regions becoming increasingly important sources of forest products while others decline. Active management of forests will be limited to those areas where high yield plantation forestry can continue to be practiced profitably.

Other unmanaged terrestrial and freshwater ecosystems have nonmarket value to humans because of their uniqueness (e.g. they may be protected in national parks), their value in maintaining genetic and biotic diversity (Peters \& Darling 1985, Graham 1988, Wilson 1988), and the general ecological context they provide for natural resources exploited by humans. Analyses have suggested that greenhouse warming may affect. worldwide distribution of vegetative life zones and biotic communities, including not only forests (Pickett \& White 1985, Overpeck et al. 1990), but also grasslands and tundra (Emanuel et al. 1985), and arid communities (Neilson 1986, 1987). Arid lands are considered particularly sensitive (Adams et al. 1978, Dregne 1983). In paleoecological studies, changes in past climates have been found to strongly influence vegetative patterns (Davis \& Botkin 1985, Prentis 1986, Webb 1986, Woodward 1987, Davis 1989a, b). Concern is growing over the effects of global warming on highly specialized terrestrial species, species with poor dispersal mechanisms, and alpine and arctic communities (Peters \& Darling 1985). Effects of global warming on aquatic communities are currently unknown, but because these communities are strongly tied to their terrestrial settings through energy, nutrients, and water (Likens 1985, Minshall et al. 1985), changes in terrestrial vegetation could have pronounced effects on freshwater systems (Minshall et al. 1983).

\section{Air quality}

Global warming is expected to affect regional and global air quality by action of a number of primary and secondary mechanisms. Primary interactions, such as direct surface warming and the resultant off-gassing of pollutants, are not as important from an air quality standpoint as secondary interactions, which result from meteorological phenomena indirectly related to temperature change. Examples of secondary interactions include

- alteration of the wind patterns, with resultant changes in ambient pollutant concentrations in some localities

- modification of stagnation periods and associated pollutant mixing parameters, with associated changes in pollutant levels

- changes of the hydrological cycle and associated storm climatology, with corresponding changes in pollutant wet-removal
- climatological modifications in levels of the solar actinic flux, which affects photochemical conversion rates (and thus the fate) of many key pollutants

- associated modification of climatic regimes, the associated vegetation, and thus the dry-deposition rates of key pollutant species.

Although there is a consensus that these features are apt to affect ambient air quality profoundly under the scenario conditions suggested by current GCM outputs, few direct or substantive predictions to this effect have appeared in the literature. A number of stochastic models of wet-removal have been published (e.g. Rodhe \& Grandell 1972), which demonstrate the strong general dependency of pollution residence times and concentrations on rainfall statistics. A variety of lowdimensional chemical models (e.g. Bruhl \& Crutzen 1988) have provided some indication of this effect under clear-air conditions. In general, these statistical and low-dimensional deterministic models can be expected to give only a qualitative indication of airquality consequences of climate change.

Major barriers to more detailed and quantitative evaluations include our present inability to execute comprehensive global chemical models within the computational constraints that currently exist and the coarse spatial resolution of the current GCMs. The first of these problems can be expected to be alleviated with faster computers and the coming generation of computer codes in chemical models. The second barrier is particularly important because many of the meteorological phenomena in the above list occur on scales that are too small to be resolved within this structure. Many of the existing regional chemical model computer codes could, for example, be adapted to provide useful air-quality predictions for global change scenarios if only they were provided sufficiently resolved meteorological fields by the GCMs. Since such GCM outputs will not be forthcoming for several years, one can expect correspondingly high levels of uncertainty in estimates of related air quality. This timeframe might be shortened somewhat by so-called limited area models, which may soon be available to provide physical interpolations of GCM output (Giorgi et al. 1989).

\section{Fisheries}

While there have been a number of studies of the relationship between past climatic variations and marine fisheries (e.g. Southward 1988), there have been fewer projections tied to global warming. According to Sibley \& Strickland (1985), the distributions of most fish species are expected to move poleward, but the magnitude of the shift and implications for yields are not known. The effect of abiotic factors on the food 
supplies of immature fish was seen as a major source of uncertainty.

Recently, a number of papers have addressed global warming and freshwater fisheries. Meisner et al. (1988) described how increased groundwater temperatures could affect survival and growth of salmonines (salmon, char, and trout) by altering temperature and dissolved oxygen in redds (nests). Areas having optimal summer conditions could shrink at low altitudes and latitudes and expand at high altitudes and latitudes.

The recent report to Congress by the US EPA (Smith \& Tirpak 1988) included an analysis of potential effects of global warming on fisheries of the Great Lakes, California, and the Southeast. In the Great Lakes region, more favorable fish habitats are expected in fall, winter, and spring with enhanced productivity of open water fish (bass, lake trout, and pike), which would more than offset less favorable summer conditions (decreased habitat, dissolved oxygen, and wetlands). Both commercial and sport fishing would benefit. In California, salinity increases in the San Francisco Bay could enhance the abundance of marine fish species, while species breeding in freshwater areas could be adversely affected. The species composition in subalpine lakes could be changed by higher temperatures and resulting increases in algal productivity. Negative effects were anticipated for coastal fisheries of the Gulf of Mexico, as finfish, shellfish, and crustaceans could be impacted by loss of coastal wetlands, temperatures above thermal tolerances, and increased salinity.

The prediction of climate change impacts on fisheries (especially marine fisheries) is crude at this time, relative to more well-studied sectors such as agriculture, for several reasons: the physical changes in habitat (e.g. water temperature and circulation patterns) are less predictable at this time than are air temperature and precipitation; fisheries, other than aquaculture, combine elements of both managed resources (i.e. economics, catch limits, and harvest technology are all important factors) and unmanaged ecosystems; and basic life-history and population-dynamics information is often inadequate because of the vastness of the seas and sampling difficulty. It is also difficult to anticipate how abiotic conditions in inland waters could be affected by global climate change because it is not yet possible to relate the output from GCMs, with their coarse spatial resolution and crude approximation of surface hydrology, to the flow, water temperature, and water quality information needed for fisheries assessment.

A recent symposium on climate change and fisheries (Regier 1988) explored a wide array of methodologies for forecasting the effects on marine and freshwater fish species and communities. The use of computer data bases on fish thermal tolerances, bioenergetic models, early response indicator species, and largescale experimental studies were among the forecasting approaches discussed. There was a consensus that there are long and complex causal chains linking climatic change with ultimate effects on fisheries stocks (e.g. DeAngelis \& Cushman 1989). A combination of methodologies can provide a range of possible futures but cannot be viewed with confidence as a source of 'predictions'

\section{Coastal zone}

Early assessments of coastal zone impacts focused on rising sea level, based on relatively simple analyses of topographic data (Schneider \& Chen 1980 for the USA, Henderson-Sellers \& McGuffie 1986 for the world). European and North American sites have provided most sea level data with which these analyses have been done (Robin 1986.) The kinds of resources at risk from rising sea level include both natural ecosystems such as wetlands (e.g. Armentano et al. 1986) and coastal structures (e.g. Kyper \& Sorensen 1985). Increased salinization of ground- and surface-water supplies (e.g. Hull \& Titus 1986) could be aggravated by precipitation and runoff decrease and threats to the operation of coastal sewage and drainage systems (e.g. Wilcoxen 1986, Titus et al. 1987). Coastal storms, such as tropical and extratropical cyclones and monsoons, can cause loss of life and considerable damage to coastal structures. The occurrence of tropical cyclones has been linked to sea surface temperature, which is expected to rise during a global warming. Although the effect on storm frequency and severity is highly uncertain, there is concern that sea surface warming could increase the frequency and severity of such storms as climate changes (e.g. Holland et al. 1987).

Smith \& Tirpak (1988) concluded that a sea-level rise of $1 \mathrm{~m}$ by the year 2100 could drown from 25 to $80 \%$ of the nation's coastal wetlands and could cost the USA about 7000 square miles of dry land. Possible responses to rising sea level, in developed areas, could include renourishment of beaches with sand pumped from offshore and construction of levees and bulkheads (with some cost to coastal plant and animal communities whose habitat may be adversely affected). Based on a predicted rise in sea level of about $1 \mathrm{~m}$ in the next $50 \mathrm{yr}$, other locations with concerns include the Netherlands, Bangladesh, the mouth of the Nile River in Egypt, coastal areas of Japan, the coastal mangrove swamps of Indonesia and Malaysia, the area of Thailand around Bangkok, and Vilan Plain in northeast Taiwan (Hekstra 1989). Calculations of the probable cost to society have been done in a few instances. For example, structural adjustments to dikes, harbors, etc., for a $1 \mathrm{~m}$ increase in 
sea level in the Netherlands would cost about $\$ 10$ billion guilders (US $\$ 5$ billion) over about 100 yr (de Ronde 1989). Major uncertainties in costing studies concern the impacts on the ecological systems in estuaries and at coastal margins, the rate of net sea level change, and the potential rate of increase in sea level after the year 2050 (Hekstra 1989). The costbenefit evaluation of protective measures is unresolved, depending in part on the value assigned to wetlands.

Uncertainty limits our ability to predict the magnitude and rate of rising sea level from global warming. In particular, it is known that coastal wetlands (Stevenson et al. 1986) and coral (Grigg \& Epp 1989) can accrete vertically and can keep up with rising sea level if the rise is not too rapid; beyond a critical rate, these systems would be inundated and destroyed. In terms of engineered systems, sea-level rise can be accommodated if not too rapid because location, planned lifetime, and maintenance of coastal structures can be adjusted (National Research Council (NRC) 1987). However, a variety of coastal processes (such as tides, storm surges, and sediment transport) and coastal ecosystem dynamics must be better understood before it is possible to predict the response of the coast to rising sea level (Mehta \& Cushman 1989). For example, in recent decades $28 \%$ of the USA mid-Atlantic coast has actually been accreting, rather than eroding (Dolan et al. 1989). Gornitz \& Kanciruk (1989) have described an ongoing project to identify those areas of the world at highest risk from rising sea level based on a combination of variables, including geology, geomorphology, tidal range, wave height, elevation, and regional trends in relative sea level and erosion/accretion.

Efforts continue to quantify the current rate of global sea-level rise and underlying processes (e.g. NRC 1985, Peltier \& Tushingham 1989). Currently, estimates through the year 2100 run from 0.5 to $2 \mathrm{~m}$, with most analyses providing estimates on the order of $1 \mathrm{~m}$ through the end of the next century.

\section{Infrastructure}

No credible estimates exist for the overall infrastructure requirements related to climate change. Issues surrounding the provision of infrastructure can be divided into 3 categories. First, there may be existing infrastructure which will simply have to be moved; e.g. it may be in the way of rising seas or it may be in place to service certain markets and populations that will migrate in response to changing climate. Second, there may exist infrastructure which will have to be modified in some way or maintained differently (e.g. storm drains may have to be enlarged, or river channels dredged more frequently). Third, new types of infrastructure may be required - some based on technologies which already exist (e.g. new canals, new bulkheads) and some based on technologies which are yet to be developed (e.g. new transportation techniques, new energy sources).

In all of these cases, changes in infrastructure may have to be designed more flexibly than in the past to anticipate and reduce social, economic and political displacements that could result from changing climate. Long-lived capital investments will require creative reaction well in advance of climate change and will therefore be possible only if we develop decisionmaking structures which can cope with enormous uncertainty, large expense, and lengthy time periods. A new understanding of intertemporal decision processes is thus required, supported by research directed toward uncovering information that is most valuable.

\section{Health effects}

Potential effects of climate change on human health have been inferred from correlation of health conditions with weather variables or seasonality. Recent studies include White \& Hertz-Picciotto (1985), Haile (1988), Kalkstein (1988), Smith \& Tirpak (1988), and Wiseman \& Longstreth (1988).

Links have not been scientifically and uncontrovertibly established between climate change and human health. Effects on human health, however, could occur through (1) the direct impacts of temperature (heat stress and cardio- and cerebrovascular conditions related to both summer and winter temperature extremes coupled, perhaps, with increased relative humidity); (2) climate-related chronic, contagious, allergic, and vector-borne diseases (e.g. influenza and pneumonia, linked to the winter seasons; asthma and hay fever, linked to plants or fungi whose ranges and life cycles are strongly affected by climate and weather; and mosquito and tick-borne diseases, such as encephalitis and Lyme disease); (3) premature birth, which has an adverse effect on human reproduction; and (4) pulmonary conditions such as bronchitis and asthma related to urban and rural smog that may increase with climate change (Raloff 1989).

Climate-induced impacts on agriculture, fisheries, water and coastal resources, and social and economic conditions might also affect human health. Decreases in food production might result in poorer diets; or rising sea levels and changed precipitation patterns might result in the deterioration of water supplies or drainage systems, with significant health and economic consequences (Harrington et al. 1989). Greater numbers of humans may migrate from one area to another, chang- 
ing the geographic ranges and susceptibility of human populations to many diseases. In general, any event that reduces standards of living will have an adverse impact on human health (Chappie \& Lave 1982).

A number of issues have yet to be resolved. Predictions of the health effects cannot be made without good predictive data on local temperatures, humidities, and levels of precipitation. Confounding factors, some much more important than weather, affect human health. The relationship of these factors (both with weather and each other) is complex, and, in many instances and global climate change might affect 2 or more factors simultaneously. We do not have the information required to accurately assess all the synergistic and offsetting effects.

Finally, we do not have much information on the social and economic impacts that climate- or ozoneinduced changes in mortality and morbidity might, in turn, generate. Nor do we have much information on the social and economic costs of such impacts. Information on the out-of-pocket medical costs and the productivity losses associated with increases in morbidity, in particular, is not readily available.

\section{FINDINGS FROM REGIONAL STUDIES}

A number of studies have attempted to produce an overall assessment of the effects of significant aspects of climate change on regional economies and societies. The US EPA's report to Congress (Smith \& Tirpak 1988) focused on 4 regions of the USA: California, the Great Lakes, the Southeast, and the Great Plains. In each region, separate (and somewhat independent) studies examined the response of different sectors to climate change. Common climate projections were taken from the GCMs of the Geophysical Fluid Dynamics Laboratory, Goddard Institute for Space Studies, and Oregon State University; sea-level rises of 50 to $200 \mathrm{~cm}$ by the year 2100 were assumed.

The following findings are taken from EPA's report to Congress. In California, global warming could cause higher winter and lower spring runoff; hurt water supplies, change the salt water/fresh water mix and the relative abundance of marine species in the San Francisco Bay; degrade water quality in alpine lakes; raise ambient ozone levels; and increase electricity demand. In the Great Lakes states global warming might lower lake levels, reduce the ice cover, and degrade water quality in rivers and shallow areas of the lakes. It could also expand agriculture in the north, change forest composition, decrease regional forest productivity in some areas, increase open water fish productivity, and alter energy demand and supply. In the Southeast. climate warming could cause forests to shift to grass- lands, losses of agricultural productivity and farms, fish and shellfish populations, and increased electricity demand. In addition, ca $90 \%$ of the national coastal wetland loss and two-thirds of the national shoreline protection costs due to climate change could occur in the Southeast. Finally, EPA found that global warming in the Great Plains might reduce agricultural output, increase irrigation demand, change water quality, and increase electricity needs.

The 'state of the art' in climate impact assessment has some significant methodological limitations. One limitation of special significance to the regional studies in the EPA report to Congress is that the regional interactions between sectors are not fully accounted for. For example, in the California regional study, the effects of changes in agriculture on water resources and of changes in water costs on agriculture are not considered. Therefore, the findings of the EPA report should be interpreted as a statement of the possible responses or vulnerability of some resource sectors to climatic change, rather than as a prediction. Ideally, a regional study should incorporate the many interactions and feedbacks that link the various sectors within the region.

Other regions of the USA have been examined by other researchers, in studies of particular resource sectors. For example, Flaschka et al. (1987) studied the response to climatic change of the Great Basin, while Idso \& Brazel (1984) and Callaway \& Currie (1985) studied basins in the Lower Colorado region. Linder \& Gibbs (1986) analyzed how electric utilities in New York State could be affected by climate change. In no case has a complete regional study been done. The first attempt to perform such a study is outlined in Cushman et al. (1989).

Potential effects of global climate warming also have been studied outside the USA, most particularly in the Netherlands, Canada, and the Soviet Union. Impacts on agriculture, forestry, and sea-level rise have received the most attention.

An IIASA worldwide case study of climate variations on agriculture (Parry et al. 1988a, b) also studied effects on timber markets. The study demonstrated economic benefits to consumers of wood products from increased boreal timber supply. It also demonstrated economic damage to supplying regions that experience only small increases in production (Sweden), that have only marginal production, or that have made large investments to grow trees (Brazil, Chile, New Zealand). Absolute values of the results were considered highly speculative owing to climatic, biological, and economic uncertainties as well as long forecast periods. More detailed study of the forest product industry is undoubtedly required.

Agriculture has been a major area of emphasis in 
international effects studies. The IIASA project pursued 11 agricultural case studies in temperate, high latitude, and semi-arid regions (Parry et al. 1988a, b) Some of the agricultural case studies were integrated into studies of the surrounding regional economies. The case studies examined the impact of variations in climate using both climate anomalies (e.g. historical single-year droughts or historical series of several cold or warm years) and synthetic estimates of climate warming from GCMs. In general, the case studies of cooler regions such as Saskatchewan (Canada), Iceland, northern agricultural areas of the Soviet Union, Finland, and Hokkaido (Japan) showed some benefits to agriculture from warmer growing season weather in cold-limited areas. If, however, precipitation also decreases, production in some of these areas (such as southwestern Saskatchewan) would be damaged by lack of moisture, moisture deficits over several years, or moisture at the wrong time. In general the IIASA studies of semi-arid regions show that interannual and intraseasonal variability in precipitation are extremely important factors in the productivity of agriculture, both in subsistence agricultural areas such as Kenya, northeast Brazil, and Ecuador, and in commercial agricultural areas such as the southern USSR and stralia.

The Canadian Climate Centre of Environment Canada has recently published a series of regional studies of the effects of climate change on various individual resource sectors in the Canadian economy, together with an assessment of sector interactions in Ontario (DPA 1988) and multiple resources in Quebec (Singh 1988). A $2 \times \mathrm{CO}_{2}$ climate change forecast from the Goddard GISS GCM was used to drive the analyses. Almost all components of the climate system and resource use in the province were affected, including municipal water use, hydroelectric power, tourism and recreation, food production, forest resources, health, and residential heating and cooling requirements. In Quebec, for example, water supply to the James Bay area was projected to increase by 7 to $20 \%$, while heating degree-days would fall by $25 \%$ in Montreal, and by $35 \%$ in Quebec City. The agricultural sector would see increases in growing seasons ranging between 22 and $72 \mathrm{~d}$, depending upon the scenario. The forestry sector would experience a loss of boreal softwood forest of around $20 \%$, but an increase of $200 \%$ in hardwood acreage. Overall, the Ontario studies were less optimistic, pointing out (for example) a decrease in net basin supply of water to the Great Lakes on the order of $15 \%$, which in turn negatively impacts water quality, tourism, hydroelectric power, and navigation on the Great Lakes (the latter somewhat offset by increased length of the ice-free shipping season). The Canadian studies also examined agricul- tural impacts in Ontario and the prairie provinces, sealevel rise in the maritime provinces, and the skiing industry in Ontario. None of the regional studies was a fully integrated regional analysis.

\section{FINDINGS FROM ANALOG STUDIES}

A number of studies have been conducted to learn the effects and responses of global climate change on human and natural systems. Early studies by historians have provided assessments of the impact of climate on human societies, for example Rotberg \& Rabb (1981), Wigley et al. (1981), and Lamb (1982). A fairly lengthy list of early analog climate impact studies is provided by Kates (1985). Properly qualified, these 'semi-descriptive' case studies may shed useful light on the relationships between society and climate change. Some of the most thorough and interesting recent assessments have been provided by Glantz and his coauthors (Glantz et al. 1987, Glantz 1988), and by the IIASA study on the impacts of climate variations on agriculture (Parry 1988a, b).

Glantz (1988) provides a number of case studies of the responses of USA and other institutions to environmental changes similar to those expected from climate change, including areas as diverse as: fluctuations in the level of the Great Salt Lake and the Great Lakes; decline in the flow of the Colorado River and drought in California; repeated freeze periods in citrus agriculture in Florida; sea-level rise in Charleston, South Carolina, and Louisiana; and variations in the navigability of the Mississippi River. Parry et al. (1988a, b) cover foreign societal responses to past historical climate-related fluctuations in agriculture. This includes relatively successful risk-minimizing cropping patterns and other institutional adaptations of indigenous peoples to climate variability of the Ecuadorian Andes, the successful food purchase programs of the Kenyan government in response to drought, and the reliance of Icelandic farmers on fodder reserves to guard against cold summers. In some cases, such as India, ad hoc or emergency responses have themselves been institutionalized to the point where the population has come to expect them (Gadgil et al. 1988). In other cases, such as the Colorado River Compact, the institutions are rigid to the point that surface water is used to grow low value crops while cities in the region are mining ground water at a high cost (Brown 1988).

In general, case studies have demonstrated how societies can respond to climate variability. For example, coalition-building among governments and interest groups has been shown to be important if action is to be taken in the face of uncertainty. All of the case studies raise the issue of intergenerational equity. The 
studies show that ad hoc responses and traditional approaches usually have been the preferred initial mode of adaptation. which in turn often added an element of rigidity to further response. Some of the studies show that once the regional winners and losers from environmental change have been identified, the winners have little incentive to compensate the losers. The analog studies contain a wealth of detail, integrate a broad range of knowledge, provide a multiplicity of perspectives, and are easy to communicate and use. The disadvantages of analog studies include lack of definite causes for environmental change that can be related to greenhouse warming (the cause is not always known) and simple failure of the analogy to be apt for a warmer world with elevated $\mathrm{CO}_{2}$ (many of the studies concern cooling and none is concerned with elevated $\mathrm{CO}_{2}$ )

\section{UNCERTAINTIES AND INFORMATION NEEDS}

This section deals with limitations on effects estimation that are posed by uncertainty or lack of information concerning biophysical and socioeconomic relationships, models, and data required to estimate the effects of climate change on the human environment. Both limitations in existing methodologies and problems with available data are addressed.

\section{Limitations in methodology}

Climate problems dominated by enormous uncertainty have, in the past, been handled by sensitivity analysis (Smith \& Tirpak 1988) and Monte Carlo simulation techniques (Nordhaus \& Yohe 1983, Edmonds \& Reilly 1985, Reilly et al. 1987). Structural uncertainty has usually been handled by examining the outputs of alternative model structures (Bolin et al. 1986). The climate change system related to biophysical and socioeconomic effects is, however, so complex that 'brute force' application of any of these techniques is not likely to be productive in providing significant insight into the important causes of certain effects or the value of information in foreseeing their potential ranges. New methods based on sound statistical theory are thus required to sort through the myriad of relevant variables if the state of the art is to be advanced in application to climate change effects.

Several criteria can be used to accomplish this sorting. Potential response variables should be included (Brainard 1967). It may, however, be possible to identify sets of collinear variables which would allow researchers to focus their attention on only one of the variables as they construct their models (see Fair 1980,
Box et al. 1987). Input designs to meet specific modeling objectives are being developed and may prove useful for sorting or ranking input variables (Sacks et al. 1989). Uncertainty about some other variables may, in addition, not be important even though their future trajectories are not well known; median or mean values of their trajectories can thus be assumed with little cost.

It can be expected that any model which provides access to social and economic effects will be composed of many sub-modules, and the relative importance of these modules can be critical. The potential range of values for variables which have a small effect on the output of an important module might be investigated thoroughly while the range of a variable which has a large effect on the output of a relatively unimportant module might be given low priority. A new methodology based on hierarchical modeling that systematically sorts on the basis of these and other criteria is currently under development as part of the DOE program described in Cushman et al. (1989). Similar methodologies are being developed in other areas that may be useful in the global modeling arena [Chapter 6 of Reimus et al. (1989) for geologic storage of nuclear waste; Gilbert et al. (1990) for an application to radioactive dose estimation!

\section{Limitations in information}

Environmental assessments of impacts from climate change have focused on individual resource sectors in selected regions of the USA. A major reason is that regional studies require a major commitment of time and money and a 'truly integrated assessment' requires a very significant commitment, such as that devoted to the National Acid Precipitation Assessment Program (NAPAP 1989).

This section focuses on the general limitations in information available for environmental assessments at the regional and national scales; detailed lists of data needs have been prepared for individual resources (White 1985). Numerically and geographically integrated data sets for environmental data do not exist for large regions (Olson 1984) - let alone economic data sets that are geographically aligned with environmental data. Economic and social data are usually collected and reported by political unit (county, census district, state), while natural resources data are often collected and reported by habitat type in physically defined areas such as watersheds or soil map units. No standard methods exist for integrating data collected for different spatial units or for defining study regions to minimize uncertainties caused by boundary heterogeneity. Large, integrated data base systems that provide data stored in compatible spatial 
and temporal formats, with associated analysis and mapping capabilities to conduct integrated studies, are rare.

This is partially true because the USA lacks a history of consistent regional and national data acquisition planning between federal and state agencies. Also, long-term maintenance of integrated data bases is difficult because of funding cycles and changes in perceived need. Examples of existing integrated data systems include the Department of Energy's GEOECOLOGY and SEEDIS, the Council of Environmental Quality's UPGRADE, the EPA's GEMS and ADDNET, and DATAGRAF (Merrill 1982, Olson 1987). Typically one third to one half of the effort spent on regional studies is devoted to developing an integrated and qualityassured data base.

Although regional studies have been performed for many years, the ecosystem properties that are important for regional scales are still poorly understood (Hunsaker et al. 1989). Few regional-scale biological models exist. In most instances, either local models will have to be scaled up with attendant scale-effect risks (Solomon 1986) or entirely new models will have to be built (Emanuel et al. 1985). The number of available models for physical processes can also be limited. For example, models are not available to adequately assess the impact of climate change on water resources at the local, regional, and national scales. Resource and economic models with input and output parameters that facilitate the linking of several resource models for the assessment of regional impacts have not been developed.

Data manipulation and extrapolation can contribute to uncertainty because of inadequate spatial or temporal resolution, or both. Point data for large geographical regions are often uneven in quality and distribution. Often it is difficult to find time series data for the same period of record for several environmental parameters. This can be especially limiting if the analog approach to assessment of impacts is being used. Some data such as land use and soil chemistry are available for only a few points in time. Computerized, digital terrain data that are of sufficient spatial resolution to be useful for coastal studies (such as land inundation from a sea-level rise of $1 \mathrm{~m}$ ) are only available for limited areas (Durfee et al. 1986, Bright 1988). The classification of geographic areas according to the relative homogeneity of one or more environmental attributes can be useful in reducing uncertainty if the classification scale is appropriate to the disturbance; however, the contribution to assessment uncertainty from such classification needs further investigation. Research is needed to assess the effects of landscape patterns in regional assessments. Some of the more recent technological tools - such as geographic information systems, satellite sensors that capture biologically significant spectral patterns, and supercomputers that can process large spatial arrays - will be useful for addressing the theoretical and applied research challenges that the regional scale poses (Hunsaker et al. 1989).

The goal of a current DOE study (Cushman et al. 1989) is to show how an integrated regional assessment of climate change can be performed. During the first year of the study, data sets and models are being developed for agriculture, water use and supply, forest resources, and economic factors. A goal of the second phase will be integration across natural resource models

\section{Dependence on forecasting future developments and interactions}

Understanding the potential effects of climate change is based on subjective views of the likely distributions of a myriad of random variables. Our ability to foresee future developments is dependent upon both temporal changes in these distributions and the 'general equilibrium' interactions among them, which work across the entire system. Bolin et al. (1986) observe that no existing model could have predicted the development of the global energy system in the 1970 s using data available in the 1950 s and 1960s; simple statistical extrapolation of price data from those years does, however, capture the 1973 and 1979 oil price shocks in the $80 \%$ confidence interval (Glynn \& Manne 1988). We need to understand that learning process as well as we understand the system itself.

Some of our learning will be Bayesian in nature simply improving our understanding of possible ranges of critical state variables by observing how they move into the future. We will learn more quickly about some variables than others, and we will need to assess the value of resources devoted to the process, weighing the relative ease of learning about each variable against its relative importance in affecting human existence. Other learning will be derived by improved understanding of underlying driving variables and the processes by which they affect the critical state variables. Recognizing, as a result, that the subjective distributions of state variables are really conditional distributions, we must also assess the value of resources devoted to investigating these variables and interactions. Still more learning will occur as we discover entirely new interactions and uncertainties. This sort of new insight can be expected to expand the range of uncertainty with which we view the future and thereby increase the value of the other types of learning. Investigation into all of these processes in the context of the 
type of long-term uncertainty of climate change effects is under way as part of the DOE effort described in Cushman et al. (1989).

\section{DISCUSSION AND SUMMARY}

To summarize, the state of science with respect to the effects of global climate change on the human environment is still in its infancy. While considerable work has been done on the impacts of climate change scenarios and historical weather on selected natural resources, the resultant economic and social consequences have not been thoroughly examined. In general, research has revealed probable qualitative effects for selected historical and synthetic climate patterns thought to be illustrative of future climate change. However, forecasting the quantitative effects of climate change remains an elusive goal for the moment. There are methodological and data-related problems of quantitatively characterizing the complex underlying interactions between man and his environment, More important, the current capability of climate models to predict climate change is limited to continental-scale effects, while events important for impact on humans occur at much smaller regional level. Table 1 summarizes the general state of the science or 'knowns', as well as the significant uncertainties. Unlike the specific rates of emission for certain of the greenhouse gases or specific parameters in equations for GCMs, where a range of values sometimes can be stated to quantify the degree of uncertainty, many of the uncertainties in the area of effects on human society are still at the conceptual or process level and are site-specific. For example, in the area of agriculture, where some of the most extensive work has been done, only the basic models of the physical mechanisms of climate change have been worked out. It is not yet clear how significant the timing of weather events and $\mathrm{CO}_{2}$ fertilization will be. In addition, it is not yet clear what the reactions of the agricultural sector (e.g. choice of crops, irrigation, and pesticide and herbicide use, planting dates) will be to weather events, though these factors will likely have a major influence on the size of impacts. The lack of detailed regional climate forecasts is a major source of uncertainty; nevertheless, there is still major uncertainty that needs to be resolved. within the models themselves.

These studies have not addressed many of the key problems in predicting the effects of climate, however, in that for analytical convenience they have focused on deterministic long run effects of climate change equivalent to a doubling of atmospheric $\mathrm{CO}_{2}$ in the steady state, typically for a few resources in isolation. They have not addressed many of the key issues, which include

- Time. Resource effects will not take place in today's world with today's technology, nor will the effects occur for the most part in a world that is steady state. Some human responses to climate change (particularly those easy to change) will be influenced at least partly by current climate conditions, not those that might eventually come to pass. Second, human response to the change in climate and its environmental effects will be determined in part by the technology available at the time - which is, in turn, a function of learning over time. The rate and timing of $\mathrm{CO}_{2}$ /climate change may be as important to determining consequences as the characteristics of an eventual steady-state $\mathrm{CO}_{2}$ /climate.

- Simultaneous multiple resource analysis. Methods must be developed to address the interactions of human and natural systems, including methods to simultaneously analyze the interaction of multiple resources within a systems framework, quantify the combined $\mathrm{CO}_{2}$ /climate change interactions, and forecast trends in exogenous system variables such as technological change and population growth. Because many economic agents in a region may compete for the same regional resource (e.g. surface water), the indirect market effects of climate change may either exacerbate or mitigate the direct effects. This implies that the analysis of impacts in a region must integrate all the significant environmental, economic, and social interactions.

- Geographic disaggregation and integration. To be meaningful, effects studies must select appropriate geographical entities for analysis - site, region, global - and because of the interactions between regions, must conduct simultaneous multiple region analysis. These effects occur either through interregional trade and market responses or through human migration. It may not be computationally feasible to directly link individual regions into a grand world model, but regional analyses must be conducted with awareness of the potential impacts on competing and neighboring regions.

- Uncertainty. Studies must develop and apply appropriate uncertainty analysis techniques. Because future climate change will be experienced as day-to-day changes in weather - temperature, precipitation, wind speed, humidity, etc. - it is uncertain what the physical consequences of climate change will be. Because we are also uncertain about both the rate of increase in greenhouse gas emissions and the resultant rate of temperature change, climate models are not accurate enough to predict weather. Because future economic growth, populations, and technologies are also uncertain, any analysis of the 
Table 1. Summary of state of the science and uncertainties in effects of global climate change on the human environment

\begin{tabular}{ll} 
Parameter or area of inquiry & Knowns \\
\hline $\begin{array}{l}\text { Findings of sectoral studies: } \\
\text { Energy }\end{array}$ & $\begin{array}{l}\text { Probable general direction of effects on con- } \\
\text { ventional energy supply (except hydro) and } \\
\text { demand, given a level of average tempera- } \\
\text { ture increase. Models and methods for short- } \\
\text { term weather variations }\end{array}$ \\
Agriculture & $\begin{array}{l}\text { Mechanisms of climate change. Physical } \\
\text { crop models with some CO } \mathrm{C}_{2} \text { fertilization from }\end{array}$ \\
laboratory experiments \\
Water resources & $\begin{array}{l}\text { Models of watersheds, ground water supply } \\
\text { and some river basins. Relationship of pre- } \\
\text { cipitation to run-off and water supply for } \\
\text { today's climate }\end{array}$ \\
Forestry and unmanaged & \\
ecosystems & $\begin{array}{l}\text { Mechanisms of climate impacts. Physical } \\
\text { models of forest succession for small plots. } \\
\text { Estimates and models of world wood pro- } \\
\text { ducts markets. Some vegetation change } \\
\text { based on fossil record }\end{array}$
\end{tabular}

Air quality

Fisheries

Coastal zone

Infrastructure

Human health

Findings of regional studies:

Findings of analog studies:

General effects of temperature on severity inversion episodes, changes in wind field patterns, and other features of air quality

General movement of marine fisheries poleward. General influence of temperatures on freshwater species

Probable rates of sea-level rise in many locations, given a scenario of temperature change. Costs of coastal defense

Some data on the influence of weather phenomena on road and building maintenance requirements, utility demand, hydroelectric supply, irrigation works. Influence of sea level on coastal infrastructure

Some inferential data on the relationship of health conditions to weather episodes, disease vectors, and climate

Impact of global warming scenarios (usually $2 \times \mathrm{CO}_{2}$ ) on individual regional resources, given current technology. Some discussion of intersectoral links, $\mathrm{CO}_{2}$ fertilization, and sensitivity of impacts to human adaptation
Uncertainties

Regional effects of climate change on weather variables. Effect of climate changes on hydroelectric supply. Effect of climate change on biomass supply and productivity of wind energy, ocean thermal, and other unconventional resources

Necessary detailed regional climate forecasts are very uncertain. Farmer responses to weather under changed climate are not clear. Because of these and other considerations, even the direction of effects on specific crops in given locations is uncertain

Necessary detailed regional and temporal forecasts of temperature, precipitation, and other weather variables. Relationships between small area precipitation and large basin water supply. Effects of changed seasonality of precipitation. Human institutional response

Regional weather inputs for forest succession models. Existence of a $\mathrm{CO}_{2}$ fertilization effect. Response of the forest industry and ecosystems to high rates of climate change. Changes in terrestrial - aquatic linkages. Role of disturbances like drought and wildfire

Likelihood of inversions (requires weather forecasts). Synergistic and offsetting effects of pollutant emissions. Sufficient spacial resolution of meteorology

Impact of institutional adaptation on environmental impacts. Reactions of human institutions to complex environmental problems with interregional, intersectoral, and intergenerational implications
Quantitative influence of warming on currents and abiotic processes. Influence of warming on precipitation, ground water, and surface water

Impact on, and value of, coastal wetland resources. Effects on land subsidence and coastal fresh ground water. Effects of coastal processes such as sediment transport

Relationship of global warming to local weather Quantitative estimates of infrastructure requirements

Influence of global warming on proximate causes of disease and health conditions. Influence of synergistic and offsetting factors

Realistic warming scenarios. Scientific basis of resource effects (e.g. open-air $\mathrm{CO}_{2}$ fertilization). Influence of human adaptation and technological change on impacts. Effects of realistic intersectoral and interregional economic and social linkages

Appropriateness of the analogs studied to a global climate change situation 
environmental consequences of climate change will have to deal explicitly with uncertainty. It is likely that this work will require advances in analytical and computational techniques.

Acknowledgements. The authors acknowledge efforts by reviewers of earlier drafts, including Tom Malone of St. Joseph's College, Erik Stenehjem and Lee Rogers of Pacific Northwest Laboratory, and Robin Graham of Oak Ridge National Laboratory. Research for this paper was partially funded by the US Department of Energy under Contract DEAC06-76RLO 1830. Pacific Northwest Laboratory is operated by Battelle Memorial Institute for the US Department of Energy under this contract. Oak Ridge National Laboratory is operated by Martin Marietta Energy Systems, Inc. for the US Department of Energy under contract DE-AC05-84OR21400. Idaho National Engineering Laboratory is operated for the US Department of Energy by EG\&G Idaho, Inc. under contract DE-AC07-76IDO1570. Substantially the same material included in this article has been published in a chapter of Energy and Climate Change, the Report of the DOE MultiLaboratory Climate Change Committee, Lewis Publishers, Chelsea, Michigan, and appears here with their permission. The views expressed in this paper are those of the authors and do not necessarily represent the views of any agency of the US Government or of the institutions with which the authors are affiliated.

\section{LITERATURE CITED}

Adams, R., Adams, M., Willens, A. (1978). Dry lands: man and plants. The Architectural Press Ltd., London

Armentano, T V., Park, R. A., Cloonan, C. L. (1986). The effect of future sea level rise on US coastal wetland areas. Holcomb Research Institute, Butler University, Indianapolis

Batie, S. S., Shugart, H. H. (1989). The biological consequences of climate changes: an ecological and economic assessment. In: Rosenberg, N. J., EasterIing, Wm. III, Crosson, P. R., Darmstadter, J. (eds.) Greenhouse warming: abatement and adaptation. Resources for the Future, Washington, D.C., p. $121-131$

Blasing, T J., Solomon, A. M. (1984). Response of the North American corm belt to climatic warming. Prog Biometeorol. 3: 311-321

Bolin, B., Doos, B. R, Jaeger, J., Warrick, R. A. (eds.) (1986). The greenhouse effect. climatic change, and ecosystems, SCOPE 29. John Wiley, Chichester

Box, G. E. P., Hunter, W., Hunter, C. (1987). An introduction to design, analysis, and model building. John Wiley and Sons, New York

Brainard, W (1967) Uncertainty and the effectiveness of policy. Am. Econom. Rev. 57(2): 411-425

Bright, E. A., Coleman, P. R., Durfee, R. C. (1988). Using U.S.G.S. 1:24,000 DLG contours to assess the impacts of rising sea levels on a coastal area. Computing and Telecommunications Division, Oak Ridge National Laboratory, Oak Ridge, Tennessee

Brown, B. G. (1988). Climate variability and the Colorado River Compact: implications for responding to climate change. In: Glantz, M. H. (ed.) Societal reponses to regional climate change: forecasting by analogy. Westview Press, Boulder, Colorado

Bruhl, C., Crutzen, P. J. (1988). Scenarios of possible changes in atmospheric temperature and ozone concentration due to man's activities, estimated with a one-dimensional photchemical climate model. Clim. Dynam. 2: 173-202
Callaway, J. M., Cronin, F. J., Currie, J. W., Tawil, J. J. (1982). An analysis of methods and models for assessing the direct and indirect impacts of $\mathrm{CO}_{2}$-induced environmental changes in the agricultural sector of the US economy. PNL4384. Pacific Northwest Laboratory, Richland, Washington

Callaway, J. M., Currie, J. W. (1985). Water resource systems and changes in climate and vegetation. In: White, $M$. R. (ed.) Characterization of information requirements for studies of $\mathrm{CO}_{2}$ effects: water resources, agriculture, fisheries, forests and human health, DOE/ER-0236, US Department of Energy, Washington D. C., p. 23-67

Chappie, M., Lave, L. (1982). The health effects of air pollution: a reanalysis. J. Urban Econom. 12(3): 346-376

Clark, J. S. (1988). Effect of climate change on fire regimes in Northwestern Minnesota. Nature, Lond. 334: 233-235

Cohen, S. J. (1986). Impacts of $\mathrm{CO}_{2}$-induced climatic change on water resources in the Great Lakes Basin. Clim. Change 8: $135-153$

Crosson, P. R., Rosenberg, N. J. (1989). Strategies for agriculture. Scientific American Special Issue on Managing Planet Earth (September 1989), p. 128-135

Cushman, R., Edmonds, J., Easterling, W., Rosenberg, N. Scott, M., Stokes, G., Yohe, G., Malone, T. (1989). Criteria for selecting a $\mathrm{CO}_{2} /$ climate change region of study. Paper 89-148.7. Presented at the 82nd Annual Meeting \& Exhibition, Air \& Waste Management Association, Anaheim, California, June 25-30, 1989. Air and Waste Management Association, Pittsburgh, Pennsylvania

Davis, M. B. (1989a). Lags in vegetative response to greenhouse warming. Clim. Change 15: 75-82

Davis, M. B. (1989b). Insights from paleoecology on global climate. Bull Ecol. Soc. Am, 70: 222-228

Davis, M. B, Botkin, D. B. (1985). Sensitivity of cool-temperate forests and their fossil pollen record to rapid temperature change. Q. Res. 23: 327-340

DeAngelis, D. L., Cushman, R. M. (1989). The potential application of models in forecasting the effects that climate changes have on fisheries. Trans. Am. Fish. Soc. (in press)

De Ronde, J. G. (1989). Past and future sea level rise in the Netherlands. In: Mehta A. J., Cushman, R. M. (eds.) Workshop on sea level rise and coasta! processes. DOE/NBB0086. US Department of Energy, Washington D.C.

DOE (U.S. Department of Energy). (1989). PC-AEO forecasting model for the annual energy outlook 1989: model documentation. DOE/EIA-M036, Energy Information Administration, Washington, D.C. 20585

Dolan, R., Trossbach, S. J., Buckley, M. K. (1989). Patterns of erosion along the Atlantic coast. In: Magoon, O. T., Converse, H., Miner, D., Tobin, L. T., Clark, D. (eds.) Coastal zone '89. American Society of Civil Engineers, New York, p. 17-22

DPA Group, Inc. (1988). $\mathrm{CO}_{2}$ induced climate change in Ontario: interdependencies and resource strategies. CCD 88-09. Chmate Change Digest, Environment Canada, Downsview, Ontario

Dregne, H. E. (1983). Desertification of arid lands. Harwood Academic Publishers, New York

Durfee, R. C., Coleman, P, R., Bonner, C. D., Bright, E. A. (1986). Terrain modeling studies to assess impacts of rising sea level on coastal landmass. Computing and Telecommunications Division, Oak Ridge National Laboratory, Oak Ridge, Tennessee

Easterling, Wm. E. III, Parry, M. L., Crosson, P. R. (1989). Adapting future agriculture to changes in climate. In: Rosenberg, N. J., Easterling, Wm., III Crosson, P. R., Darmstadter, J. (eds.). Greenhouse warming: abatement and adaptation. Resources for the Future, Washington, D.C., p. $91-104$ 
Edmonds, J. A., Reilly, J. M. (1985). Global energy assessing the future. Oxford University Press, New York

Emanuel, R. R., Shugart, H. H., Stevenson, M. P. (1985) Climatic change and the broad-scale distribution of terrestrial ecosystem complexes. Clim. Change 7. 26-43

Fair, R. (1980). Estrmating the expected predictive accuracy of econometric models. Int. Econom. Rev. 21(2): 355-378

Flaschka, I., Stockton, C. W., Boggess, W. R. (1987). Climatic variation and surface water resources in the Great Basin region. Wat. Res. Bull. 23(1): 47-57

Frederick, K. D., Gleick, P. H. (1989). Water resources and climate change. In: Rosenberg, N. J., Easterling, Wm. III Crosson, P. R., Darmstadter, J. (eds.) Greenhouse warming: abatement and adaptation, Chap. 10. Resources for the Future, Washington, D.C., p. 133-143.

Frederick, K. D., Kneese, A. V. (1989). Western water allocation institutions and climate change. In: Waggoner, P. E. (ed.) Climate and water. John Wiley, New York, p. 395-419

Gadgil, S., Muda, A. K. S., Jodha, N. S., Singh, R. T,, Virmani, S. M. (1988). The effects of climatic variations on agriculture in dry tropical regions of India. In: Parry, M. L., Carter, T. R. Konijin, N. T. (eds.) The impact of climatic variations on agriculture: Vol. 2. Assessments in semiarid regions Kluwer Academic Publishers, Dordrecht, The Netherlands, p. $497-580$

Garcia, R. (1981). Drought and man: the 1972 case history Vol. 1. Nature pleads guilty. Pergamon Press, New York

Gates, W. L. (1985). The use of general circulation models in the analysis of the ecosystem impacts of climatic change. Clim. Change 7: 267-284

Gilbert et al. (1990). Statistical aspects of reconstructing the 131 -iodine dose to the thyroid of individuals living near the Hanford site in the mid-1940s. PNL-SA-17384-HEDR, Pacific Northwest Laboratory, Richland, Washington

Giorgi, F., Bates, G. T., Enrico, R. M., Dickenson, R. C. (1989). Modeling the climate of the western U.S. with a limited area model coupled to a general circulation model. Papers 6.1 American Meteorological Society 6th Conference on Applied Climatology. American Meterological Society, Boston, Massachusetts

Glantz, M. H. (ed.) (1988). Societal responses to regional climate change: forecasting by analogy. Westview Press, Boulder

Glantz, M., Katz, R., Krenz, M. (eds.) (1987). The social impacts associated with the 1982-83 worldwide climate anomalies. National Center for Atmospheric Research, Boulder

Gleick, P. H. (1987a). The development and testing of a water balance model for climate impact assessment: modeling the Sacramento Basin. Wat. Resour. Res. 23: 1049-1061

Gleick, P. H. (1987b). Regional consequences of increases in atmospheric $\mathrm{CO}_{2}$ and other trace gases. Clim. Change 10 $137-161$

Glynn, P.. Manne, A. (1988). On the valuation of payoffs from a geometric random walk on oil prices. Pacif. Asian $\mathrm{J}$ Energy $2(1): 47-48$

Gornitz, V., Kanciruk, P. (1989). Assessment of global coastal hazards from sea level rise. In: Magoon, O. T., Converse H., Miner, D., Tobin, L. T., Clark, D. (eds.) Coastal zone 89. American Society of Civil Engineers, New York, p. 1345-1359

Graham, R. W. (1988). The role of climatic change in the design of biological reserves: the paleoecological perspective for conservation biology. Conserv. Biol. 2 (4): 391-394

Grigg, R. W., Epp, D. (1989). Critical depth for the survival of coral islands: effects on the Hawaiian archipelago. Science 243: 638-641
Haile, D. G. (1988). Computer simulation of the effects of changes in weather patterns on vector-borne disease transmission. Report prepared for US EPA, Office of Policy, Planning, and Evaluation. US EPA Project No DW12932662-01-1

Harrington, W., Krupnick, A. J., Spofford, W. O., Jr (1989) The economic losses of a waterborne disease outbreak. J of Urban Econom. 25 (1): 116-137

Hekstra, G. (1989). Sea level rise: regional consequences and responses. In: Rosenberg N. J., Easterling, Wm. IlI, Crosson, P. R., Darmstadter, J. (eds.) Greenhouse warming: abatement and adaptation. Resources for the Future, Washington, D.C., p. 53-67

Henderson-Sellers, A., McGuffie, K. (1986). The threat from melting ice caps. New Scientist 110:24-25

Holland, G. J., McBride, J. L., Nicholls, N. (1987). Australian region tropical cyclones and the greenhouse effect. In: Greenhouse. E. J. Brill, Kinderhook, New York, p. 438-455

Hull, C. H. J., Titus, J. G. (1986). Greenhouse effect, sea level rise, and salinity in the Delaware Estuary. EPA 230-05-86010. US Environmental Protection Agency, Washington, D.C.

Hunsaker, C. T., Graham, R. L., Suter, G. W., O'Neill, R, V., Jackson, B. L., Barnthouse, L. W. (1989). Regional ecological risk assessment: theory and demonstration. ORNL/ TM-11128. Oak Ridge National Laboratory, Oak Ridge, Tennessee

Idso, S. B., Brazel, A. J. (1984). Rising atmospheric carbon dioxide concentrations may increase streamflow. Nature, Lond. 312: 51-53

Jaeger, J. (1983). Climate and energy systems: a review of their interactions, John Wiley \& Sons, New York

Kalkstein, L. S. (1988). The impact of $\mathrm{CO}_{2}$ and trace gasinduced climate change upon human mortality. EPA, Office of Policy, Planning, and Evaluation. US EPA Project No. CR81430101, US Environmental Protection Agency, Washington, D.C.

Kates, R. W., Ausubel, J. H., Berberian, M. (eds.) 1985. SCOPE 27 Climate impact assessment. Studies of the interaction of climate and society. John Wiley and Sons, New York

Klan, M., Belzer, D. B., Marsh, S. J., Moore, N. L., Roop, J. M., Sands, R. D. (1989). Energy use and conservation trends: 1972-1986. PNL-6714, Pacific Northwest Laboratory, Richland, Washington

Kyper, T N., Sorensen, R. M. (1985). The impact of selected sea level rise scenarios on the beach and coastal structures at Sea Bright, N. J. In: Magoon, D. T. (ed.) Coastal zone '85. American Society of Civil Engineers, New York, p. $2645-2661$

Lamb, H. H. (1982). Climate history and the modern world. Metheun, London

Likens, G. E. (1985). The aquatic ecosystem and air-landwater interactions. In: Likens, G. E. (ed.) An ecosystem approach to aquatic ecology, Mirror Lake and its environment. Springer-Verlag, New York

Linder, K. P., Gibbs, M. J. (1986). The potential effects of climate change on electric utilities: New York case study results. Presented to New York State Energy Research and Development Authority. ICF Incorporated, Washington, D.C.

Martin, Ph., Rosenberg, N. J., McKenney, M. S. (1989). Sensitivity of evapotranspiration in a wheat field, a forest and a grassland to changes in climate and direct effects of carbon dioxide. Clim. Change 14: 117-151

Maxwell, J. B., Barrie, L. A. (1989). Atmospheric and climatic change in the Arctic and Antarctic. Ambio 18 (1): 42-49

Mehta, A. J., Cushman, R. M. (eds.) (1989). Workshop on sea 
level rise and coastal processes. DOE/NBB-0086. US Department of Energy, Washington, D.C.

Meisner, J. D., Rosenteld, J. S., Regier, H. A. (1988). The role of groundwater in the impact of climate warming on stream salmonines. Fisheries 13 (3): 2-8

Merrill, D. (1982). Overview of integrated data systems: context, capabilities, and status. In: Proc. 1982 Integrated Data Users Workshop, Olson, R. J., Millemann, N. T (eds.), CONF-8210120, Oak Ridge National Laboratory, Oak Ridge, Tennessee, p. 3-24

Miller, W. F., Dougherty, P. M., Switzer, G. L. (1987). Effect of rising carbon dioxide and potential climate change on loblolly pine distribution, growth, survival, and productivity. In: Shands, W. E., Hoffman, J. S. (eds.) The greenhouse effects, climate change, and U.S. forests. The Conservation Foundation, Washington, D.C. p. 157-187

Minshall, G. W., Peterson, R. C., Cummins, K. W., Bott, T L., Sedell, J. R. (1983). Interbiome comparison of stream ecosystem dynamics. Ecol. Monogr. 53: 1-25

Minshall, G. W., Cummins, K. W., Peterson, R. C., Cushing, C. E., Bruns, D. A., Sedell, J. R., Van Note, R. L. (1985) Developments in stream ecosystem theory. Can. J. Fish aquat. Sci. 42 (5): 1045-1055

National Acid Precipitation Assessment Program (NAPAP) (1989). Plan and schedule for NAPAP assessment reports, 1989-1990. Washington, D.C.

National Research Council (1985). Glaciers, ice sheets, and sea level: effect of a $\mathrm{CO}_{2}$-induced climatic change. DOE/ ER/60235-1. US Department of Energy, Washington, D.C.

National Research Council (1987). Responding to changes in sea level. Committee on Engineering Implications of Changes in Relative Mean Sea Level, Commission on Engineering and Technical Systems. National Academy Press, Washington, D.C.

Neilson, R. P. (1986). High resolution climatic analysis and Southwest biogeography. Science 232: 27-34

Neilson, R. P. (1987). Biotic regionalization and climatic controls in western North America. Vegetatio 70: 135-147

Nordhaus, W., Yohe, G. (1983). Future carbon dioxide emissions from fossil fuels. Changing Climate. National Research Council, Washington, D.C.

Olson, R. J. (1984). Review of existing environmental and natural resource data bases. ORNL/TM-8928. Oak Ridge National Laboratory, Oak Ridge, Tennessee

Olson, R. J., Allison, L. J., McCollough, I. L. (1987). ADDNET notebook: documentation of the Acid Deposition Data Network (ADDNET) data base supporting the National Acid Precipitation Assessment Program. ORNL/TM-10086. Oak Ridge National Laboratory, Oak Ridge, Tennessee

Overpeck, J. T., Rind, D., Goldberg, R. (1990). Climaticinduced changes in forest disturbance and vegetation. Nature, Lond. 343: 51-53

Parry, M. L., Carter, T. R., Konijin, N. T. (eds.) (1988a). The impact of climatic variations on agriculture, Vol. 1. Assessments in cool temperate and cold regions. Kluwer Academic Publishers, Dordrecht

Parry, M. L., Carter, T R., Konijin, N. T (eds.) (1988b). The impact of climatic variations on agriculture, Vol. 2. Assessments in semiarid regions. Kluwer Academic Publishers, Dordrecht

Pastor, J., Post, W. M. (1988). Response of northern forests to $\mathrm{CO}_{2}$-induced climate change. Nature, Lond. 334: 55-58

Peltier. W. R., Tushingham, A. M. (1989). Global sea level rise and the greenhouse effect: might they be connected? Science 244: 806-810

Peters, R. L., Darling, D. J. S. (1985). The greenhouse effect and nature reserves. BioSci. 35 (11): 707-717
Pickett, S. T. A., White, P. S. (eds.) (1985). The ecology of natural disturbance and patch dynamics. Academic Press, New York

Prentice, I. C. (1986). Vegetative responses to past climatic variation. Vegetatio 67: 131-141

Raloff, J. (1989). Global smog: newest greenhouse projection. Science News 135 (17): 262-263

Regier, H. A. (organizer) (1988). Symposium on climate change and fisheries, 118th Annual Meeting of the American Fisheries Society, Toronto, Canada Trans. Am. Fish. Soc. (in press)

Reilly, J. M., Edmonds, J. A., Gardner, R. H., Brenkert, A. L. (1987). Uncertainty analysis of the IEAJORAU $\mathrm{CO}_{2}$ emissions model. The Energy Journal 8 (3): 1-29

Reimus, P. W., Apted, M. J., Liebetrau, A. M. (1989). List and preliminary ranking of key parameters for nuclear waste package performance assessment. In: Apted, M., et al. Performance Assessment Center for Engineered Barriers (PACE Program): F4 1988 Summary Report. PNC SA 0865.89-001. Battelle, Pacific Northwest Laboratories, Richland, Washington

Riebsame, W. (1989). Assessing the social implications of climate fluctuations: a guide to climate impact studies. World Climate Impacts Programme, United Nations Environmental Programme, Nairobi

Robin, G. de Q. (1986). Changing the sea level. Bolin, B., Doos, B. R., Jaeger, J., Warrick, R. A. (eds.) Scope 29: The greenhouse effect, climatic change, and ecosystems. John Wiley and Sons, New York, p. 323-362

Rodhe, H., Grandell, J. (1972). On the removal time of aerosol particles from the atmosphere by precipitation scavenging. Tellus 24: 442-454

Rosenberg, N. J. (1981). The increasing $\mathrm{CO}_{2}$ concentration in the atmosphere and its implication on agricultural productivity, I. Effects on photosynthesis, transpiration and water use efficiency. Clim Change 3: 265-279

Rosenberg, N. J., McKenney, M. S., Martin, Ph. (1989). Evapotranspiration in a greenhouse warmed world: a review and a simulation. Agricult and For. Meteorol. 47: 303-320

Rosenzweig, C. (1985). Potential $\mathrm{CO}_{2}$-induced climate effects on North American wheat-producing regions. Clim. Change 7: 367-389

Rotberg, R. I., Rabb, T, K. (eds.) (1981). Climate and history. Princeton University Press, Princeton

Sacks, J., Schiller, S. B., Welch, W. J (1989). Designs for computer experiments. Technometrics 31 (1): 41-48

Schlesinger, M. E., Mitchell, J. F. B. (1985). Model projections of the equilibrium climatic response to increased carbon dioxide. In: MacCracken, M. C., Luther, F. M. (eds.) Projecting the climatic effects of increasing carbon dioxide, Chap. 4. DOE/ER-0237, Department of Energy, Carbon Dioxide Research Division. Washington, D.C.

Schneider, S. H., Chen, R. S. (1980j. Carbon dioxide warming and coastal flooding: physical factors and climatic impact. Ann. Rev. Energy 5: 107-140

Sedjo, R. A., Solomon, A. M. (1989). Climate and forests. In: Rosenberg, N. J., Easterling, Wm. III, Crosson, P. R., Darmstadter, J. (eds.) Greenhouse warming: abatement and adaptation. Resources for the Future, Washington, D.C., p. 105-119

Sibley, T H., Strickland, R. M. (1985). Fisheries: some relationships to climate change and marine environmental factors. In: Characterization of information requirements for studies of $\mathrm{CO}_{2}$ effects: water resources, agriculture, fisheries, forests and human health, White, M. R. (ed.) DOE/ER-0236, US Department of Energy, Washington, D.C., p. $95-143$ 
Singh, B. (1988). The implications of climate change for natural resources in Quebec. CCD 88-08. Climate Change Digest, Environment Canada, Downsview, Ontario

Smit, B. (1989). Climate warming and Canada's comparative position in agriculture. CCD 89-01. Climate Change Digest, Environment Canada, Downsview, Ontario

Smith, J. B., Tirpak, D. A. (eds.) (1988). The potential effects of global climate change on the United States. US Environmental Protection Agency, Washington, D.C

Solomon, A. M. (1986). Transient response of forests to $\mathrm{CO}_{2}$ induced climate change: simulation modeling experiments in eastern North America. Oecologia (Berl.) 68: 567-579

Southward, A. J., Boalch, G. T., Maddock, L. (1988). Fluctuations in the herring and pilchard fisheries of Devon and Cornwall linked to change in climate since the 16th century. J. mar. biol. Ass. U.K. 68: 423-445

Stevenson, J. C., Ward L. G, Kearney, M. S. (1986) Vertical accretion in marshes with varying rates of sea level rise. In: Wolfe, D. A. (ed.) Estuarine Variability, Academic Press, New York, p. 241-259

Titus, J. G. (1988). Greenhouse effect, sea level rise, and coastal wetlands. EPA-230-05-86-013. US Environmental Protection Agency, Washington, D.C

Titus, J. G., Kuo, C. Y., Gibbs, M. J., LaRoche, T B., Webb, M. K., Waddell, J. O. (1987). Greenhouse effect, sea level rise, and coastal drainage systems. J. Wat. Resour Planning Management 113: 216-227

Topping, J. R. (ed.) (1989). Coping with climate change: Proceedings of the Second North American Conference on Preparing for Climate Change: a cooperative approach. The Climate Institute, Washington, D.C.

Webb, T. III. (1986). Is vegetation in equilibrium with climate? How to interpret late-Quaternary pollen data. Vegetatio 67: 75-91

Editor: Professor V. Meentemeyer
Waggoner, P. E. (1983). Agriculture and a climate changed by more carbon dioxide, In: Changing Climate, National Academy Press, Washington, D.C., p. 383-418

White, M. R. (ed.) (1985). Characterization of information requirements for studies of $\mathrm{CO}_{2}$ effects: water resources, agriculture, fisheries, forests and human health. DOE/ ER-0236, US Department of Energy, Washington, D.C.

White, M. R., Hertz-Picciotto, I. (1985). 'Human health: analysis of climate related to health. 'Characteristics of information requirements for studies of $\mathrm{CO}_{2}$ effects: water resources, agriculture, fisheries, forests, and human health. DOE/ ER-0236. US Department of Energy. Office of Energy Research, Washington, D.C.

Wigley, T. M. L., Ingram, J. J., Farmer, G. (eds.) (1981). Climate and history studies in past climates and their impact on man. Cambridge University Press, London

Wilcoxen, P. J. (1986). Coastal erosion and sea level rise: implications for Ocean Beach and San Francisco's Westside transport project. Coast. Zone Management J. 14: 173-191

Wilks, D. S., (1988). Estimating the consequences of $\mathrm{CO}_{2}$ induced climatic change on North American grain agriculture using general circulation model information. Clim. Change 13: $19-42$

Wilson, E. O. (ed.) (1988). Biodiversity. National Academy Press, Washington, D.C.

Wiseman, J., Longstreth, J. D. (1988). The potential impact of climate change on patterns of infectious disease in the United States. Background paper and summary of a workshop. Report to US EPA. Project No. 68-10-7289

Woodward, F. I. (1987). Climate and plant distribution. Cambridge University Press, Cambridge

World Bank (1984). World development report 1984. Oxford Univ. Press, New York

Manuscript first received: November 4, 1989

Revised version accepted: April 5, 1990 
